\title{
Work, employment and psychiatric disability
}

\section{Jed Boardman}
Abstract Unemployment is high among those with mental disorders, particularly severe mental disorders, and there are a range of social and economic barriers impeding their employment. In general, there is a lack of vocational rehabilitation services in the UK for people with both physical and mental illnesses, despite good evidence for the effectiveness of some work schemes. Here, the need is discussed for a national strategy for vocational rehabilitation that involves employment and health services, and covers both physical and mental disorders.

Work is important both in maintaining mental health and in promoting the recovery of those who have experienced mental health problems. Enabling people to retain or gain employment has a profound effect on many areas of life and the costs of unemployment are high. Employment for individuals with mental illness gives opportunities for them to participate in society as active citizens, and barriers to them doing so are linked to stigma, prejudices and discrimination. Participating in work and employment can be seen as therapeutic endeavours, but also as important indicators of a successful outcome.

Employment opportunities for mentally ill people are an important concern for those working in mental health services, not least because they form part of the rehabilitation and reintegration efforts associated with these services. Secondary mental health services focus on people with severe and enduring mental illnesses, for whom there are limited employment opportunities. However, those with common mental disorders, mainly anxiety and depression, also have employment difficulties and it is recognised that vocational services for these people are lacking.

A recent report on vocational rehabilitation by the British Society of Rehabilitation Medicine (2001) recognised that such services are inadequately provided in the UK for those with physical and mental ill-health and that early, professional and accessible vocational rehabilitation should be available to all following illness or injury.

\section{Work, employment and leisure}

The American novelist William Faulkner observed that work is 'just about the only thing that you can do for eight hours a day'. Traditional definitions of work emphasise that it is an activity that involves the exercise of skills and judgement, taking place within set limits prescribed by others (Bennett, 1970). Work is therefore essentially something you 'do' for other people. By contrast, in most leisure activities you can 'please yourself'.

'Employment' is work you get paid for. Many activities, for example childcare, housework and looking after elderly or sick relatives, are 'work', as the tasks and outcomes involved are defined by others. However, as they do not at present usually attract formal payments, they are not 'employment'. 'Work' and 'employment' are very important in the context of mental health problems, because the overwhelming majority of people with such problems want to be engaged in some kind of meaningful activity that uses their skills and meets the expectations of others (they want to 'work'). However, not all wish to be 'employed', with all the additional stresses and responsibilities that entails.

\section{Employment rates and mental illness Common mental disorders}

The Office of Population Censuses and Surveys (OPCS) surveys of psychiatric morbidity in Great

Jed Boardman is a consultant psychiatrist at the South London and Maudsley NHS Trust (Chaucer Community Resource Centre, 13 Ann Moss Way, London SE16 2TH, UK) and a senior lecturer in social psychiatry at the Institute of Psychiatry, London. He was Chairman of the Royal College of Psychiatrists' Working Group on Employment Opportunities and Psychiatric Disability (Royal College of Psychiatrists, 2003). His clinical interests include the development of community-based services for delivery of psychiatric care and his research interests include health service resesarch, epidemiology and psychiatric disorders in primary care. 
Box 1 Unemployment and sickness absence in those with neurotic disorders: OPCS findings (Meltzer et al, 1995)

- Adults with neurotic disorder were 4-5 times more likely than the rest of the sample to be permanently unable to work

- Overall, $61 \%$ of men with one neurotic disorder and $46 \%$ with two disorders were working ( $v .77 \%$ of those with no disorder). The equivalent figures for women were $58 \%$, $33 \%$ and $65 \%$

- The lowest rates of employment among people with neurotic disorders were found in those with phobias: $43 \%$ of men and 30\% of women with phobias were working

- Among the sample with any neurotic disorder who were unemployed and seeking work, $70 \%$ had been unemployed for a year or more (i.e. $7 \%$ of all people with a neurotic disorder)

- Compared with the general population, adults with neurosis were twice as likely to be receiving income support (19\% v. 10\%) and 4-5 times more likely to have invalidity benefit $(9 \%$ v. $2 \%)$

Britain found significant levels of unemployment and sickness absence in those with neurotic disorders (Meltzer et al, 1995) (Box 1).

General practitioners (GPs) provide the main source of care for most people with psychiatric disorders, the bulk of whom have non-psychotic syndromes. The unemployed consult their GPs more often than does the general population and those who have been unemployed for more than 12 weeks show between four and ten times the prevalence of depression, anxiety and somatic illness.

\section{Long-term mental illness}

There are low rates of employment in people with severe mental illness. The Labour Force Survey, a continuous household survey carried out in Great Britain that provides figures on those with long-term disabilities, shows that people with enduring mental health problems are much less likely to be economically active than those with physical or sensory impairments (National Statistics Office) (Box 2).

\section{Costs of mental illness and unemployment}

About 80 million working days are lost every year in the UK due to mental illness, with the cost to employers amounting to $£ 1.2$ billion. An average of
3000 British people move onto incapacity benefits each week and the leading causes of this are musculo-skeletal problems (28\%) and psychiatric disorders (20\%). In 1993, 1 in 5 days of certified work incapacity in the UK was due to mental ill health, which accounted for 92 million lost working days.

The estimated annual total cost of mental illness in England at 1996/1997 prices is $£ 32.1$ billion; the component costs include $£ 11.8$ billion in lost employment, $£ 7.6$ billion in Department of Social Security payments and $£ 4.1$ billion in National Health Service costs (Patel \& Knapp, 1998).

\section{Why is work important?}

Work plays a central role in all people's lives, and this has been recognised since ancient times. There are five main arguments for the promotion of employment for people with mental health problems (Schneider, 1998), and these are outlined below.

\section{Social and health benefits}

Employment provides a monetary reward and is inseparable from economic productivity, with its profits for the employer and its material benefits for society. In addition, employment provides latent benefits - non-financial gains - to the worker. These additional benefits include social identity and status; social contacts and support; a means of structuring and occupying time; activity and involvement; and a sense of personal achievement (Warr, 1987). Work tells us who we are and enables us to tell others who we are; typically, the first questions that we ask when we meet someone are 'What is your name?' and 'What do you do?'

Unemployment is associated with physical ill health, including premature death (Wilson \& Walker,

Box 2 Employment of people with long-term mental illness in Great Britain in spring, 2000 (National Statistics Office, 2000)

- Long-term disabled people with mental health problems as the main difficulty represent $8 \%$ of long-term disabled people of working age; $18 \%$ of this group were in employment in 2000

- Long-term disabled people with no mental health difficulties at all represent $84 \%$ of long-term disabled people of working age; $52 \%$ were in employment in 2000

- $30-40 \%$ of long-term disabled people with mental health problems as the main difficulty are capable of holding down a job 
1993; Bartley, 1994), and there is a particularly strong relationship between unemployment and mental health difficulties. Work is crucial for people with mental health problems, as they are especially sensitive to the negative effects of unemployment and the associated loss of structure, purpose and identity (Bennett, 1970). Already socially excluded as a result of their mental health problems, their exclusion is aggravated by unemployment.

Unemployed people do not exploit the extra time they have available for leisure and social pursuits. Their social networks and social functioning decrease, as do motivation and interest, leading to apathy. Social isolation is often particularly problematic for people who experience mental health problems, and work is effective in increasing social networks.

\section{Demand from service users}

Despite the high rates of unemployment among people with mental health problems, studies indicate that as many as $90 \%$ would like to go back to work (Grove, 1999; Secker et al, 2001).

There is increasing policy emphasis on the importance of service users' preferences and wishes in the provision of services (Department of Health, $1999,2000)$ and mental health service users clearly say that they want to have the opportunity to work. Assisting people to gain and sustain employment should be considered a valid 'treatment' in its own right, which assists in achieving many of the targets for mental health services.

\section{Ideological argument: work as a rights issue}

The right to work is enshrined in Article 23 of the United Nations Declaration of Human Rights, which states that 'everyone has the right to work, to free choice of employment, to just and favourable conditions of work and to protection against unemployment' (United Nations, 1948). Yet the majority of people who experience longer-term mental health problems continue to be denied this right. Discrimination on the part of potential employers is undoubtedly a major obstacle preventing people with mental health problems, especially those with diagnoses of schizophrenia, form gaining work (Manning \& White, 1995).

\section{Economic argument: work as an economic issue}

Enormous amounts of public money, in the form of social security payments, are spent on supporting people out of work. If some of this resource could be redirected towards enabling people to maintain and/or regain employment, then the social, psychiatric and economic gains are likely to be large.

\section{National policy and the new context of mental health care}

The running down of the large psychiatric hospitals, which provided most of the work projects in the UK for those with long-term psychiatric disabilities, has placed most mental health services and their users in community settings.

\section{Barriers to employment and to employment services development}

Figures on employment and mental illness suggest that mental health service users face more significant barriers to work than do other disabled people. Only people with a severe learning disability find it more difficult to get paid work. The high rates of unemployment among those with mental illnesses, coupled with their desire to obtain work, suggests that work projects that do exist are providing only a limited and restricted service. Some of these barriers are listed in Box 3.

Box 3 Barriers to employment facing mental health service users

- Historically, the employment of disabled people has depended on economic growth, overall rate of employment and times of labour shortage (Warner, 1994)

- The welfare system has built-in disincentives to returning to work (the 'benefits trap')

- In open employment, people with a history of mental illness face stigma, a reluctance to employ them and the risk of failure

- Mental health professionals, GPs and employers can underestimate the capacities and skills of mentally ill people and overestimate the risk to employers

- A model of mental illness that emphasises episodes and 'cure', as opposed to one that focuses on the disabilities of people with longterm mental illness, dominates

- Many mental health professionals lack expertise in business development

- Evidence is scarce relating to the types of service and approaches that are effective in getting those with mental illness back to work and keeping them in employment 


\section{Psychiatric illness or disability?}

The commonly held model of illness emphasises the episodic nature of disorders, and this may be less appropriate in the present context than a model emphasising the enduring problems associated with mental illness. There are therefore advantages in adopting a 'disability' framework for improving employment opportunities.

\section{The illness model}

The 'illness model' assumes that an episode occurs for which treatment is available and a cure achieved. Such a model may be useful when applied to acute mental illness, especially in the context of acute in-patient services or for many of the problems seen by mental health services.

\section{The disability model}

In contrast, disabled people cannot normally expect a 'cure', but can adapt to changed circumstances and can increasingly expect adjustments in the world around them to enable them to participate. They can expect contributory action from others, rather than waiting to 'get better'.

Disability can be understood to mean the interaction between an impairment (being blind, or unable to walk, or having long-term cognitive difficulties as a result of schizophrenia) and the social structures and barriers that exclude the affected individual from full participation. In this sense, 'disability', unlike 'illness', brings into focus the need to remove barriers in social attitudes, practices, policies and the built environment. This 'social model of disability' sees disability as an interaction between a person's impairment and the social barriers that he or she faces (Oliver, 1990). The benefits of a social model of disability are shown in Box 4.

\section{Work schemes}

Historically, occupation has formed an important part of the care of mentally ill people, but work schemes in the UK have been principally in the form of sheltered employment and have been linked to the large asylums. The running down of the large mental hospitals, and the eventual closure of many of them during the 1990s, was associated with the development of community-based mental health services. These were not always commensurate with the loss of the hospital services and less emphasis was placed on work schemes, which became fragmentary. The increase in employment during the latter years of the 20th century has been accompanied by an expansion of employment schemes for people with mental illnesses. Shifted in location from hospital to community, these are often run by non-statutory agencies.

\section{Sheltered employment}

Traditional sheltered workshops and sheltered employment factories such as those run by Remploy do not provide employment in the open market. They may be of value for those who find open employment difficult and as a means of introducing people to the work situation. They tend to have very low rates of movement into open employment and they often find it difficult to be commercially viable.

\section{Prevocational training}

Prevocational training is one way of helping people with severe mental illness return to work. It assumes that these people require a period of preparation before entering into competitive employment. This preparation includes sheltered workshops, transitional employment (working in a job that is 'owned' by a rehabilitation agency), skills training, work crews and other preparatory activities. These approaches are not ends in themselves.

\section{Supported employment}

Supported employment places clients in competitive jobs without extended preparation and provides on-the-job support from employment specialists or trained 'job coaches' (Becker et al, 1994). The client is hired and paid by a real employer and is entitled to the full company benefits. From the beginning, both employee and employer receive enough help from a support organisation to ensure success.

\section{Box 4 Benefits of a social model of disability}

- It offers a more helpful conceptual basis for understanding and promoting employment opportunities for people who use mental health services and offers more hope of recovery of social roles

- It better captures the experience of discrimination and exclusion central to the lives of many mental health service users and addresses the barriers to employment

- It is consistent with current government policy (e.g. the Disability Discrimination Act 1995)

- It is consistent with the views of users and people with disabilities

- It assists in achieving dialogue with employers 
Box 5 The core principles of supported employment

- The goal is competitive employment in work settings integrated into a community's economy

- Clients are expected to obtain jobs directly, rather than after lengthy pre-employment training

- Rehabilitation is an integral component of treatment of mental health rather than a separate service

- Services are based on clients' preferences and choices

- Assessment is continuous and based on real work experiences

- Follow-on support is continued indefinitely

The core principles of supported employment are listed in Box 5.

There are several types of supported employment programmes, for example, the assertive community treatment model, transitional employment (such as the clubhouse approach) and the job coach model (Bond et al, 1997). The model that emerges from the literature as the most promising programme so far is known as individual placement and support (Becker et al, 1994). In this programme, the emphasis is on rapid placement in work, with intensive support and training on the job.

\section{The clubhouse model}

Clubhouses aim to assist people with long-term mental health problems to address issues such as low self-esteem, low motivation and social isolation. They promote social inclusion and support people in leading productive and meaningful lives within the community. The clubhouse model is based on principles of meaningful activity and psychosocial rehabilitation, and work is a central factor in its operation.

\section{Social firms}

A possible solution to the problem of providing highquality sheltered work and employment that is being developed in many parts of Europe, including the $\mathrm{UK}$, is the social firm (Grove \& Drurie, 1999). This is sometimes described as a modern version of sheltered employment, but there are crucial differences.

In a social firm, the emphasis is on creating a successful business that can support paid employment. The social firm operates entirely as a business, but its methods emphasise participation by employees in all aspects of the enterprise.
Although it may offer training on a commercial basis, it is not primarily engaged in 'rehabilitation' and its core staff, whether or not disabled themselves, are paid the going rate for the work. About half the staff will be disabled people, and members from the disabled workforce may be in managerial positions.

Cooperatives can operate like social firms or social enterprises, but they are owned and managed democratically by their members. Social enterprise is the name adopted by small businesses that operate semi-commercially, but which have a training or rehabilitation function.

\section{Opportunities for volunteering}

For many people, making a contribution in a voluntary capacity, particularly to an activity that they regard as socially worthwhile, may also be a valuable part of their lives. For disabled people, there is often added value in volunteering to help others as 'experts by experience'. There are many opportunities for volunteering and many agencies that can act as brokers between the need and the people who can meet it. The volunteer role, and the process needed to enable disabled people to become volunteers, requires exactly the same kinds of support as paid employment.

\section{User employment programmes}

The principles of supported employment have been used to great effect in a number of schemes across the UK in which NHS trusts have committed themselves to the employment of service users. 'Personal experience of mental health problems' is thus specified as either a 'desirable' or an 'essential' qualification in specifications for such posts.

In these schemes, people with mental health problems are employed in existing posts on the same terms and conditions as other employees and a programme of support for those who need it is built into the normal employment practices of the Trust. The effect of the scheme has been interesting on a number of levels, not only creating jobs but also challenging many of the barriers and misconceptions about employing people with mental health problems (Perkins et al, 1997).

\section{Work schemes in the UK}

It is not known how many different types of work scheme operate in the UK and how many people are receiving services. Recent surveys estimate that there are at least 135 organisations offering sheltered employment, 77 providing open employment and about 50 social firms (Grove \& Durie, 1999; Crowther et al, 2001). A survey in the north-west of England 
found high variation in provision and a poor relationship between the schemes identified and the needs of the areas in which they operated (Crowther \& Marshall, 2001). There was a more than 40-fold variation in provision across health authority areas, and the highest level of provision was in an area with the lowest deprivation and unemployment.

\section{Effectiveness of work schemes}

A number of studies have reviewed the effectiveness of work schemes, and most evidence comes from studies conducted in the USA (Bond et al, 2001; Crowther et al, 2001). Several randomised controlled trials have compared prevocational training with supported employment. Prevocational training assumes that people with severe mental illness require a period of preparation before entering into open employment. Supported employment places people in competitive jobs without extended preparation and provides on-the-job support from employment specialists or job coaches. In general, supported employment is more effective than prevocational training at helping people with severe mental illness to obtain and keep competitive employment. Sheltered employment schemes have been largely unsuccessful at achieving open employment for those with severe mental illnesses.

More work needs to be done on the effectiveness of such schemes, particularly in the UK. Of particular importance are their cost-effectiveness, clinical and social outcomes and job retention. Some components critical to successful schemes are shown in Box 6 .

\section{Assessment for employment}

There is scope for improvement in our common understanding of 'assessment for employment' across professional fields with an interest in psychiatric disability and employment. Two matters should be recognised. First, there is the predictive importance of historical factors. As in other areas of social functioning, there tends to be a strong relationship between work history and future occupational functioning. Detailed work histories are more useful in assessment than are most clinical measures: diagnosis or traditional psychometric testing such as IQ or aptitude measures have very limited predictive value when it comes to occupational performance. Second, there is the importance of personal factors such as motivation, confidence and personal objectives. They have consistently been shown to be highly predictive of outcomes and are generally superior to traditional skills or IQ assessments. Thus, if a person really wants to do the job, then she is more likely to succeed.
Box 6 Key components of successful employment schemes

- The agency providing supported employment is committed to competitive employment as an attainable goal for those with severe mental illness

- Supported employment programmes use a rapid job search approach to helping clients obtain jobs directly (rather than providing lengthy pre-employment assessment, training and counselling)

- Staff and clients find individual job placements according to client preferences, strengths and work experiences

- Follow-up support is maintained indefinitely

- Supported employment programmes are closely integrated with mental health teams

In the assessment and planning process, the main components are whether people really want to work, what their skills are and what they are interested in doing. Once these have been established, a programme of support and training is designed for each individual, aimed at achieving that person's personal goals and ambitions.

The work setting, the characteristics of the individual and the desired outcomes should be considered when thinking about a comprehensive range of work opportunities. As with other areas of psychiatry, outcomes will be determined by a combination of historical factors (work history, skills, previous work performance); individual factors (confidence, motivation, personal aims and objectives); and setting factors (expectations of staff, opportunities for training and development, links to other programmes and so on). The assessment process must therefore begin by examining these variables. It is important to find out if an individual wants (or has) a job as early as possible in the contact with health services. Both job retention and job placement should be considered at this time.

Motivation is contingent and is linked to success, mastery and other factors. Getting a job can change a person's outlook and attitude to work, so premature exclusion of apparently unmotivated individuals may deny them the chance they need to move on in life. Assessment is a skilled task and should be considered as an intervention in its own right.

\section{Health agencies and employment schemes}

The provision of employment opportunities for people with psychiatric disabilities inevitably involves working across a variety of different 
agencies and involves many different agencies and professional groups. The key agencies within the health services are general practice, adult general psychiatric services (mainly community mental health teams and rehabilitation services) and occupational medicine.

No single model of service is right for everyone and each approach may help different people at different times in their recovery and reintegration. Ideally, people should have access to a range of work, training and support that is relevant to their changing needs. They should have the opportunity for progression towards paid employment, but they should not be forced to move on to situations of greater stress and responsibility if they do not wish to. Thus, it is generally agreed that a comprehensive mental health employment service in any given locality should offer a 'spectrum of opportunities', with possibilities to gain access to these at any point and to move on, or to stay at the same level, according to individual needs (Grove, 1999).

There will be people whose disabilities are too great to be supported in open employment (or, at least, for a part of their illness career), regardless of the extent of available support. For these people, other approaches to work and structured activity will be needed.

It is adult psychiatry services that are mainly involved with employment issues, as they see adults of working age. However, specialist services such as those providing for people with drug and alcohol problems also have a role. The important components of mental health services for vocational rehabilitation are shown in Box 7.

At present, mental health services place insufficient emphasis on returning people to work and there is no specific provision for work schemes or work liaison schemes in community mental health teams (CMHTs). The National Service Framework for Mental Health (Department of Health, 1999) and its associated documents, while implicitly offering opportunities for mental health services to develop employment schemes, does not give direct emphasis on developing rehabilitation services. There is a need for all CMHTs to have access to a range of work schemes and these should be based along the lines indicated by the available evidence. This central role of CMHTs in local services for people with severe mental illnesses can only be achieved through the improvement of rehabilitation and day care services in the areas in which teams operate and by enhancing the skills of team members. There is also the need to identify vocational specialists within CMHTs.

Members of CMHTs will need additional training to assist with the delivery of occupational services. This will require the introduction of the concepts of rehabilitation and work in the training of psychiatrists, nurses and others into the multidisciplinary team, as well as skills development and awareness training and information on disability discrimination legislation.

The Government's National Plan also requires that advice on welfare benefits be part of the Care Programme Approach and this needs to be integrated. The Welfare to Work scheme, for which the lead agency is the local authority social services' department, also requires that benefits advice be integrated with employment assessment. Each CHMT may soon need to identify a 'benefit lead' and a 'vocational lead', who would work closely together. Welfare and benefits advisers can help users to achieve the range of benefits available to them and can give appropriate advice on benefits and work.

Although facilitation of employment opportunities is now fundamental to general community mental health services, in the past it would have been seen as a role of specialist rehabilitation services (which still exist in some areas as providers of employment opportunities). Additionally, specialist service providers have a role in meeting the needs of the most disabled people, including mentally disordered offenders, who have an additional disadvantage in the labour market.

\section{Box 7 Important components of mental health services for vocational rehabilitation}

- Community mental health teams - these play a central role in the delivery of National Service Framework standards, along with crisis teams, assertive outreach teams and services for those with first-onset psychosis

- In-patient services and associated residential units - they can be important in rehabilitation following an acute episode of illness (Boardman \& Hodgson, 2000)

- Day hospitals and day centres - day care needs to be expanded to provide facilities with close working links with CMHTs and providing a range of services, both acute and chronic, therapeutic and supportive. Rehabilitation should be a central aim and work, activity and employment central goals. The clubhouse model is one example of this expanded concept

- The Care Programme Approach may be of assistance in highlighting vocational needs in a patient's care plan. All care plans in the Care Programme Approach for people with more serious health difficulties must now show plans to secure suitable employment or other occupational activity 


\section{References}

Bartley, M. (1994) Unemployment and ill health: understanding the relationships. Journal of Epidemiology and Community Health, 48, 333-337.

Becker, D. R., Drake, R. E. \& Concord, N. H. (1994) Individual placement and support: a community mental health center approach to rehabilitation. Community Mental Health Journal, 30, 193-206.

Bennett, D. (1970) The value of work in psychiatric rehabilitation. Social Psychiatry, 5, 224-230.

Boardman, A. P. \& Hodson, R. (2000) Community in-patient units and halfway hospitals. Advances in Psychiatric Treatment, 6, 120-127.

Bond G. R., Drake, R. E., Mueser, K. T., et al (1997) An update on supported employment for people with severe mental illness. Psychiatric Services, 48, 335-346.

-, Becker, D. R., Drake, R. E., et al (2001) Implementing supported employment as evidence-based practice. Psychiatric Services, 52, 313-322.

British Society of Rehabilitation Medicine (2001) Vocational Rehabilitation: The Way Forward. BSRM Working Party Report. London: BSRM.

Crowther, R. E. \& Marshall, M. (2001) Employment rehabilitation schemes for people with mental health problems in the North West Region: service characteristics and utilisation. Journal of Mental Health, 10, 373-382.

—, - Bond, G. R., et al (2001) Helping people with severe mental illness to obtain work: systematic review. $B M J$ 322, 204-208.

Department of Health (1999) National Service Framework for Mental Health. Modern Standards and Service Models. London: Department of Health

- (2000) The NHS Plan: A Plan for Investment, a Plan for Reform (Cm 4818-I). London: Stationery Office.

Grove, B. (1999) Mental health and employment: shaping a new agenda. Journal of Mental Health, 8, 131-140.

— \& Drurie, S. (1999) Social Firms - An Instrument for Economic Empowerment and Inclusion. Redhill: Social Firms UK.

Manning, C. \& White, P. D. (1995) Attitudes of employers to the mentally ill. Psychiatric Bulletin, 19, 541-543.

Meltzer, H., Gill, B., Petticrew, M., et al (1995). Economic Activity and Social Functioning of Adults with Psychiatric Disorders. OPCS Surveys of Psychiatric Morbidity in Great Britain. Report No. 3. London: HMSO.

National Statistics Office (2000) Labour Force Survey. London: National Statistics Office.

Oliver, M. (1990) The Politics of Disablement. Basingstoke: Macmillan.

Patel, A. \& Knapp, M. (1998) Costs of mental illness in England. PSSRU Mental Health Research Review, 5, 4-10.

Perkins, R. E., Buckfield, R. \& Choy, D. (1997) Access to employment. Journal of Mental Health, 6, 307-318.

Royal College of Psychiatrists (2003) Employment Opportunities and Psychiatric Disability (Council Report CR111). London: Royal College of Psychiatrists.

Schneider, J. (1998) Work interventions in mental health care: some arguments and recent evidence. Journal of Mental Health, 7, 81-94.

Secker, J., Grove, B. \& Seebohm, P. (2001) Challenging Barriers to Employment, Training and Education for Mental Health Service Users. The Service Users' Perspective. London: Institute for Applied Health \& Social Policy, King's College London.

United Nations (1948) Universal Declaration of Human Rights. http://www.un.org/Overview/rights.html

Warner, R. (1994) Recovery from Schizophrenia. Psychiatry and Political Economy (2nd edn). London: Routledge.
Warr, P. (1987) Work, Unemployment and Mental Health. Oxford: Oxford University Press.

Wilson, S. \& Walker, G. (1993) Unemployment and health. A review. Public Health, 107, 153-162.

\section{Multiple choice questions}

1 In Great Britain:

a adults with long-term mental illness have high employment rates

b people with musculo-skeletal problems and psychiatric disorders make up about $50 \%$ of those receiving incapacity benefits

c adults with neurotic disorder are less likely to be permanently unable to work than the general population

d adults with long-term physical disability are less likely to be in employment than those with long-term mental health problems

e the longer a person with a neurotic disorder is out of work, the more difficult it is to return to work.

\section{Employment:}

a is generally an activity that you get paid for

b provides latent benefits for the worker

c may provide structure, purpose and identity

$\mathrm{d}$ is generally rejected by users of mental health services

e may benefit physical health.

3 With regard to work schemes:

a social firms may be managed by people with disabilities

b supported employment is a new form of sheltered workshop

c prevocational training offers preparation for the person before entering open employment

$\mathrm{d}$ prevocational training is more effective than supported employment in helping people with mental illness obtain open employment

e supported employment schemes are more successful when closely integrated with mental health teams.

\section{MCQ answers}

$\begin{array}{lllll}\text { 1 } & & 2 & 3 \\ \text { a F } & \text { a T } & \text { a T } \\ \text { b T } & \text { b T } & \text { b F } \\ \text { c F } & \text { c T } & \text { c T } \\ \text { d F } & \text { d F } & \text { d F } \\ \text { e T } & \text { e T } & \text { e T }\end{array}$

